\title{
HOUSE ON FIRE: UM CASO DE ARTE POLÍTICA E COLABORATIVA
}

\author{
Teresa Mora
}

\begin{abstract}
Resumo
Neste artigo, a arte política é pensada na confluência de quatro tendências das práticas artísticas na atualidade: a viragem social, a urgência da realidade, o impulso utópico, e as práticas colaborativas. Tal confluência é articulada com o pressuposto de que as práticas de arte política, assim configuradas, estão, pelo menos em parte, a potenciar a transição para um modelo colaborativo entre cultura artística e cultura científico-social e filosófica. Perspetivada a arte nesta dupla vertente - política e colaborativa -, o artigo focaliza-se numa investigação em progresso sobre a rede de teatros e festivais europeus House on Fire. O material que apoia a investigação é relativo ao período 2012-2015 da ação da rede, sendo composto por planos de atividade e programas. A análise do material qualitativo é ainda suportada por anotações feitas pela investigadora na qualidade de espetadora-investigadora. Os objetivos que enquadram o estudo são os seguintes: estabelecer o estatuto de agente de arte política da House on Fire; identificar, na sua programação, os focos temáticos de crítica societal; e elaborar uma tipologia exploratória das várias modalidades de colaboração entre cultura artística e cultura científico-social e filosófica.
\end{abstract}

\section{Palavras-chave}

Impulso utópico; práticas colaborativas; repertórios de ação científicosocial e filosófica; urgência da realidade; viragem social

\begin{abstract}
In this article, political art is perceived at the confluence of four trends in artistic practices today: the social turn, the reality urgency, the utopian impulse, and the collaborative practices. This confluence is articulated on the assumption that political art practices are, at least to a certain point, enhancing the transition to a collaborative model between artistic culture and social scientific and philosophical culture. Framed by this double perspective on art - political and collaborative -, this article is drawn from a major study about the House on Fire European network of festivals and theatres. The qualitative data that support this research consists of House on Fire's activity plans and programmes from 2012 to 2015. The qualitative data was also analysed by resorting to research notes taken by the researcher in the position of spectator. This study is guided by the following aims: to explore the political agency position of House on Fire; to identify the focus of society criticism in the House on Fire's programmes; and to construct an exploratory typology of collaborative modalities between artistic culture and social-scientific and philosophical culture.
\end{abstract}

\section{Keywords}

Collaborative practices; scientific-social and philosophical action repertoires; social turn; reality urgency; utopian impulse 


\section{ARTE POLÍticA E COLABORATIVA: SINAIS E PRESSUPOSTOS}

Desde o final dos anos 9o, um pouco por todo o mundo, em particular na Europa, e em Portugal também, tem-se assistido a um processo de dinamização de práticas artísticas que, em modalidades várias, das artes visuais às artes performativas, e em formatos interdisciplinares ou transdisciplinares, parece estar a ser marcado pela tendência para a diluição da tradicional divisão institucional entre cultura artística, de um lado, e cultura científico-social e filosófica, do outro. São vários os exemplos.

O Museu Reina Sofía desenvolveu uma linha editorial de responsabilidade social e reflexão política, desde o primeiro número (primavera-verão 2010) da revista Carta, que tem significativamente o subtítulo de Revista de pensamento y debate del Museo Nacional Centro de Arte Reina Sofía. O "Próximo Futuro" - Programa Gulbenkian de Cultura Contemporânea - 2009 a 2015 - foi, sob o comissariado de António Pinto Ribeiro, marcado por um eixo duplo: "trabalho de investigação e produção teóricas" (em colaboração com centros de investigação) e "trabalho de produção e criação artísticas" (em valências várias, teatro, música, cinema, fotografia), ambos divulgados, de entre outros meios, através das Grandes Lições (2013) que contaram entre os seus autores com economistas, historiadores, humanistas, poetas, sociólogos e artistas.

$\mathrm{Na}$ Europa e nos Estados Unidos, das diversas exposições institucionais de artes plásticas que entre 2011 e $2013^{2}$ puseram em diálogo arte e utopia, "Sin realidad no hay utopía", exibida primeiro em Sevilha (2011) e, depois, em S. Francisco (2013), baseou-se na "reflexão crítica do filósofo Jean Baudrillard e do professor de literatura alemã Andreas Huyssen" (Cardoso \& Lobo, 2013, p. 311). Esta exposiç̧ão organizou-se em secções sobre a "mentira" dos políticos e quatro "colapsos", do comunismo, do capitalismo, da democracia e da geopolítica.

Poder-se-iam referir muitos outros exemplos para dar a ver "novas experiências institucionais", materializando, inclusive, o diálogo entre movimentos sociais, universidades e centros de investigação, como é o caso da Universidad Nómada, em rede, com - CENDEAC (Centro de Documentación y Estudios Avanzados de Arte Contemporáneo), em Murcia (Rodríguez, 2012, p. 41). O que através dos vários casos mencionados pretendo aqui equacionar é o papel de relevância política que os agentes artístico-culturais (curadores, diretores, artistas) parecem estar cada vez mais a desempenhar no contexto de crítica ao modelo de sociedade no qual estamos cada vez mais a viver, desde o início do século XXI, e em particular na Europa.

Por arte política entendo "a arte que distende o questionamento do modo de organização da sociedade nas suas estruturas de poder e de dominação" (Mora, 2016, p. 6). Corroborando André Carmo, ao seguir de perto Boyan Manchev, acordemos que, "manifestando-se no seio de uma imensa constelação de práticas artísticas, a arte política é-o

\footnotetext{
' Retirado de http://www.proximofuturo.gulbenkian.pt/proximo-futuro

${ }^{2}$ Without Reality There Is No Utopia, Yerba Buena Center for the Arts de S. Francisco (EUA), 25 fev. a 2 jun. 2013; Sin realidad no hay utopia, Centro Andaluz de arte Contemporânea, Sevilha, 2011; Utopia, Hoxton Art Projects Gallery, Londres, jan. a mar. 2012; The Spirit of Utopia, White Chapel Gallery, Londres, jul. a set. 2013; Utopien in Kleinen Masstab, Trienal de Escultura em Miniatura de Feelbach, Alemanha, jun. a set. 2103.
} 
precisamente porque tem o potencial necessário para se opor aos regimes de soberania, dominação e opressão" (Carmo, 2014, p. 120). Para os nossos dias, considere-se como pressuposto que o modo de organização da sociedade que nos é mais próximo, aquele comummente designado por modelo euro-americano, pode ser sintetizado, entre outros, nos seguintes traços: "a voracidade do capitalismo; a instalação de uma política neoliberal; a fragilidade da democracia; o quebranto do contrato social; o desmantelamento do Estado Social" (Mora, 2016, p. 5); a "recomposição do Estado em mecanismo de mercadorização" (Bernardo, 2015, p. 14); "o avanço do fascismo social" (Santos, 2002, 2006, 2007); e a ameaça ecológica.

É também de salientar, de um ponto de vista analítico, que a importância política que os agentes artístico-culturais podem, na atualidade, estar a desempenhar é susceptível de ser revelada a dois níveis:

pela reflexão que agenciam em torno do modelo de sociedade referido; (...) por intentarem suscitar por meio da prática artística outras possibilidades de atenuar problemas sociais, e outros modos de viver e de vivermos em conjunto, apelando, com maior ou menor grau de explicitação, a uma vida outra - justa e de bem estar social. (Mora, 2016, p. 5)

Pressuponho, ainda, que é o próprio desenvolvimento de práticas da arte política que parece, pelo menos, em parte, estar a potenciar a transição para um modelo colaborativo entre cultura artística e cultura científico-social e filosófica. Por último, e de um modo mais geral, a atual potência política da arte deve, do meu ponto de vista, ser equacionada na confluência de quatro tendências que estão, desde o final do século XX, a marcar as práticas artísticas: "a viragem social; a urgência da realidade; o impulso utópico; e as práticas colaborativas" (Mora, 2016, p. 5).

Ao usar a expressão "potência" política da arte, o que aqui convoco é o contraste e simultaneamente a relação de oposição entre a noção habitual de potere (poder), ou seja, o "poder sobre", e a noção de potentia (potência), na acepção de Espinosa e tal como desenvolvido por Negri, isto é, o "poder de" no sentido de realizar um ato, o que quer dizer, por exemplo, que "eu atualizo a potencialidade humana de nadar se aprendo efetivamente a nadar" (Keucheyan, 2013, p. 125). Em termos da oposição entre os dois poderes, o poder, no sentido habitual, "consiste em separar os indivíduos da sua potência", ao passo que "atualizar uma potência, consiste, inversamente, em derrubar os entraves com que o poder submete os indivíduos" (Keucheyan, 2013, p. 125).

\section{ARTE POLÍ́tICA E \#4}

A viragem social (social turn) evocada por Claire Bishop $(2006,2012)$ transporta-nos para uma numerosa lista de conceitos: “"new genre public art' (Lacy, 1995); 'esthétique relationnel' (Bourriaud, 1998); 'conversational art' (Bhabha, 1998); 'dialogue-based public art' (Finkelpearl, 2000); 'dialogical art' (Kester, 2005); 'participatory art' (Bishop, 2006); 'collaborative art' (Kester, 2011), etc.” (Mora, 2016, p. 5). Apesar de se 
referenciarem a uma variedade de práticas artísticas e raízes discursivas que inscrevem entre si linhas conflituais (Malzacher, 2015, p. 17), estes conceitos não deixam de ter como "denominador comum a forte tendência para a arte assumir, em declinações várias, o seu valor social (ou relacional)" (Mora, 2016, p. 5). Neste sentido, cada um destes conceitos, provenientes na sua larga maioria do campo artístico, revela, cada um a seu modo, uma mesma tendência, nas artes, para se aproximarem da lógica relacional (ou social) que (tradicionalmente) preside às ciências sociais, trate-se da relação identitária eu-outro (na antropologia), das relações intra ou intergrupo (na psicologia social), ou das relações sociais (na sociologia).

A urgência da realidade ou a reality trend - advogada pelo movimento teatral Theatre der Zeit (surgido, em 2002, com o teatro documental de não-artistas levados à cena pelo coletivo Rimini Protokoll) - tem uma das suas expressões mais significativas no "agenciamento artístico do debate público sobre o mundo em que vivemos e os seus problemas societais concretos", o que vem relevar "a proximidade entre o valor de conhecimento resultante da prática artística e o conhecimento sobre o mundo atual produzido na prática científico-social" (Mora, 2016, p. 6).

A arte política no que tem de pensamento crítico "radica não só na posição de negação que uma determinada prática artística põe em movimento mas também na inscrição do movimento alternativo de abertura a outros modos possíveis de estar/ser/ viver" (Mora, 2016, p. 6). Trata-se, pois, da tendência para o desenvolvimento de práticas artísticas que são assumidas pelos seus protagonistas como práticas alternativas, num duplo sentido: o de se fazerem portadoras de uma linguagem emancipatória da exploração, da dominação, da estigmatização, da periferialização; e o de apelarem, com maior ou menor grau de explicitação, às possibilidades de uma vida outra, justa e de bem-estar social. Também nisto da tendência para o empenhamento político ativo não estamos longe de algumas das práticas das ciências sociais e da filosofia política, de entre as quais aquelas filiadas na tradição marxista, ou as que configuram o pensamento crítico contemporâneo, re-emergente desde o final da década de 90 (Keucheyan, 2013; Unipop, 2014).

O interesse desta investigação é o de persistir na pesquisa de "práticas artísticas em que o movimento de negação do instituído se abra (...) a um 'exercício' de exploração dos 'possíveis laterais' à realidade que Ruyer definiu como sendo próprio do 'modo utópico' de pensamento" (Mora, 2016, p. 6). Este jogo de "transbordo dos limites do mundo conhecido" (Mora, 2009, p. 1) leva-me a inscrever o elemento "utopia" na conceptualização da arte política. Por arte política designo, então, a arte que, ao operar ações que se pensam como ações de negação/crítica do mundo em que vivemos, incorpora, com uma intensidade e um potencial alternativo variáveis, o elemento de ruptura e abertura que designo por impulso utópico.

A arte colaborativa, sendo eminentemente relacional (ou social), é-o em declinações várias: ao supor uma agência plural de artistas com investigadores sociais, ativistas, associações, administrações locais, etc., trabalhando em co-autoria ou estabelecendo relações de horizontalidade (Hand, 2010, pp. 14-15); ao inscrever projetos de 
fazer-inter-agir diretamente indivíduos, grupos, residentes, comunidades, ou outras constelações de sujeitos; ao atuar em escalas simbólicas e territoriais muito diversas no espaço público, na rua, no bairro, na escola, na prisão, na casa-abrigo, no hospital, na comunidade terapêutica, etc., em modalidades de agenciamento várias, por exemplo, de sensibilização, de participação, de cidadania, de sustentabilidade; ao ter por objetivo melhorar situações ou condições reais (materiais e/ou simbólicas) de pessoas e de populações; ao atuar em contextos, políticos, económicos, culturais, de transgressão, segregação, exclusão, guetização, estigmatização, discriminação, periferialização, privação, degradação...

De entre a diversidade de práticas colaborativas, relativamente aos seus intervenientes e objetivos, refiram-se alguns exemplos. O projeto "A festa acabou" (2006-2009), que foi realizado no bairro Quinta da Vitória, em Loures (na área metropolitana de Lisboa), por uma equipa de artistas visuais, curadores, antropólogos e moradores (Borges, 2012), configurou-se como um projeto de intervenção local e participada, ao procurar "criar uma imagem do bairro informada pelos próprios moradores, que constituísse um contraponto às imagens veiculadas pela opinião pública, associadas ao crime, à violência e à pobreza" (Borges, 2012, p. 200). O projeto "We-traders - Troca-se Crise por Cidade", promovido, desde 2013, pelo Goethe-Institut e concebido com a dupla curadoria da artista e designer Rose Epple e da arquiteta Angelika Fitz, constitui uma rede de conhecimento e divulgação de iniciativas de artistas, designers, investigadores..., em cinco cidades europeias, Lisboa, Madrid, Toulouse, Turim e Berlim, no contexto das quais os projetos colaborativos aí produzidos inscrevem objetivos muito diversos, agenciados por coletivos autónomos. Por exemplo, Lisboa conta com cinco projetos muito distintos: a "Cozinha Popular da Mouraria", a "Agulha num Palheiro", "O Espelho", "A Linha" e o "BIP/ZIP".

É esta dinâmica de institucionalização de colaborações interdisciplinares com o objetivo geral de constituir colectivos de ação movidos por projetos vários de natureza social (ou relacional) que também parece estar a constituir uma tendência no campo específico da arte política.

\section{CONTORNOS DE UMA INVESTIGAÇÃO}

Em Portugal, a rede de dez teatros e festivais europeus House on Fire ${ }^{3}$, fundada em 2011 pelo Maria Matos - Teatro Municipal de Lisboa, constitui um caso propício ao objetivo de investigar a tendência para a diluição das fronteiras entre práticas artísticas e conhecimento científico-social e filosófico, no contexto da arte política, nomeadamente pelo facto do Maria Matos (MM) - o teatro fundador e coordenador da rede - se assumir na sua prática discursiva como um agente de arte política e, simultaneamente,

\footnotetext{
${ }_{3}^{3}$ Constituída por: Maria Matos Teatro Municipal/EGEAC - Lisboa (Portugal) - coordenador; Kaaitheater - Bruxelas (Bélgica), Bergen Internasjonale Teater - Bergen (Noruega); ARCJA Theatre - Praga (República Checa); Théâtre Garonne Toulouse (França); Frascati - Amesterdão (Holanda); MALTA Festival - Poznan (Polónia); BRUT - Viena (Áustria); HAU/ Hebbel Theater - Berlim (Alemanha); LIFT/London International Festival of Theatre - Londres (Grã-Bretanha); apoiada, no período 2012-2017, pelo Programa Cultura da União Europeia.
} 
desenvolver uma atividade de programação na qual o seu papel de agente promotor do modelo de colaboração entre cultura artística e cultura científico-social e filosófica se revela recorrente e consistente.

O material empírico que sustenta a investigação que tenho vindo a desenvolver sobre a House on Fire reporta-se ao período 2012-2015 da sua atividade e compreende os seguintes elementos documentais: o site de divulgação da rede ao público ${ }^{4}$, o Plano de atividade (junho 2012 - dezembro 2014), a Proposta artístico-cultural do MM (outubro 2014 - setembro 2018), os programas de divulgação da programação do MM e as folhas de sala disponibilizadas ao público.

Os resultados aqui apresentados apoiam-se neste material documental, referenciado ao nível do polo discursivo da House on Fire, relativo ao MM, dado o seu estatuto de teatro fundador/coordenador. Nesta fase da investigação não são abordadas as companhias artísticas que integram a rede, entendidas estas como nós discursivos que virão, numa fase posterior, a ser trabalhados, seletivamente, a partir dos seus meios específicos de divulgação, nomeadamente os seus próprios sites, e as entrevistas de artistas veiculadas na imprensa. De modo complementar, uma parte dos resultados decorrem, ainda, de notas resultantes das incursões que desde julho de 2013 fui fazendo no terreno do MM. No início, como simples espetadora de alguma da sua programação e, mais tarde, como observadora participante, o que veio a permitir-me, por um lado, ir re-vendo nas práticas artísticas a materialização dos enunciados discursivos da programação que havia previamente coletado e lido e, por outro, ir procedendo à sua reorganização já como espetadora-investigadora.

É no cruzamento de dois eixos - político e colaborativo - que o material acima enunciado é estudado. No eixo político, estabelece-se o estatuto de agente de arte política como traço fundador da rede House on Fire e identificam-se, para o período 2012-2015 da sua programação, os focos temáticos de crítica societal. No eixo colaborativo, através da exploração de "repertórios de ação" (Tilly, 1986) ou stocks de meios de ação - temas, problemáticas, autores, teorias ou conceitos, obras - provenientes dos regimes discursivos científico e filosófico, procura-se tipificar as várias modalidades de colaboração entre cultura artística e cultura científico-social-filosófica ocorrentes na House on Fire, também no período 2012-2015 da sua programação.

\section{HOUSE ON FIRE E ARTE POLÍ́tICA}

O estatuto de agente de arte política da House on Fire é desde logo assinalável pelo "pendor crítico da própria designação" (Mora, 2016, p. 6): Fire "significa urgência"; House "representa a sustentabilidade que procuramos". Este compromisso é explicitado no documento que detalha a sua ação: "os co-organizadores da House on Fire esforçam-se por internacionalizar e partilhar os fortes impulsos criativos do novo paradigma da responsabilidade social e do ativismo político que está a emergir nas artes performativas e

4 Disponível em http://www.houseonfire.eu/home 
nas artes em geral"5. O "valor de conhecimento da prática artística no debate público" (Mora, 2016, p. 7) sobre a sociedade atual é afirmado de modo inequívoco.

Nos últimos anos, uma mudança radical ocorreu nas artes do espetáculo e do mundo das artes em geral. Artistas, curadores, diretores de teatro e agentes culturais começaram a reivindicar o seu lugar no debate público sobre as questões sociais, ambientais e políticas, argumentando que os artistas têm um papel ativo a desempenhar na sociedade e que a criação artística oferece uma fonte específica e válida de conhecimento e experiência. ${ }^{6}$

Por último, “ao teatro é atribuído o estatuto de 'espaço público' (no sentido de Habermas)" (Mora, 2016, p. 7):

assumimos que o Teatro Maria Matos tem uma responsabilidade na estimulação do debate público. Encaramos o teatro como um espaço de reflexão sobre o estado do mundo e acreditamos que o encontro entre a criação artística e o pensamento crítico pode ser uma arma poderosa contra a indiferença e a falta de iniciativa cívica. (Depputer citado em Mora, 2016, p. 7)

A atividade crítica desenvolvida pela rede House on Fire é programaticamente organizada pelo MM à escala transnacional dos dez países que a contextualizam. Assim, conforme se lê na Proposta Artístico-Cultural do MM (2014):

com a criação da (...) House on Fire (...), os temas avançados no contexto do programa (...) são trabalhados em colaboração com os parceiros da rede, passando por encomendas conjuntas de obras de arte, organização partilhada de conferências e palestras, partilha de contactos e informação e discussão de ideias e projetos. (Deputter, 2014)

A potência política que caracteriza a rede está igualmente correlacionada com a abertura organizacional a saberes e a agentes provenientes de outras culturas para lá das artes performativas, entre as quais a cultura científico-filosófica, as organizações/ associações cívicas e o cidadão comum. Esta diluição de fronteiras constitutivas de um modelo cultural colaborativo é nitidamente observável nas várias características que são enunciadas na Proposta Artístico-Cultural do MM (2014) enquanto argumentos da atividade crítica que se propõe desenvolver. Assim, uma das características enunciadas é a de "promover contactos entre áreas de conhecimento radicalmente diferentes", numa lógica de horizontalidade, onde as "análises académicas" e os "discursos filosóficos" surgem a par das "aproximações artísticas", das "participações das associações cívicas" e das próprias "experiências da vida quotidiana" (Deputter, 2014). Outra das características apresentadas é a focalização da rede em programas de "Debate \& Pensamento", num "esforço sustentado para juntar artistas, pensadores e espetadores na discussão de temas importantes da atualidade, entre os quais 'Governação', 'Tempo', 'Público/

\footnotetext{
${ }^{5}$ House on Fire: detailed description of the action, s/d. (policopiado, 11 págs.).

${ }^{6}$ House on Fire: detailed description of the action, s/d. (policopiado, 11 págs.).
} 
Privado', 'Manifesto'” (Deputter, 2014). Uma última característica a destacar é o estabelecimento de colaborações com agentes externos à rede, sendo, por um lado, de assinalar a procura de "organizações independentes como a Unipop, o Baldio, a organização Londrina Julie's Bycicle, a iniciativa cultural alemã FuturZwei ou o movimento Cidades em Transição" (Deputter, 2014) e de salientar, por outro, os contactos que são privilegiados, através dos parceiros da rede, com diversas instituições académicas europeias de entre as quais a Universidade Von Humbolt (Berlim), a New Economics Foundation (Londres), o Institute for European Studios (Bruxelas), a Universidade de Amesterdão, e o Institut fur Theater, Film und Medienwissenschaft (Viena).

A atividade crítica da rede House on Fire exerce-se por meio de programas de "Debate \& Pensamento", à escala transnacional (dos parceiros da rede), desenvolvidos com base em três tipos de atividades: coprodução de criações nas artes performativas que vão da pequena à grande escala, reportando-se a artistas mais experientes ou emergentes e contemplando diversos formatos performativos (teatro, dança, performance, happening, etc.); coorganização de eventos culturais multidisciplinares; publicação on-line de copy-books (na língua original de cada país e em tradução inglesa), relativos às atividades da rede (que incluem entrevistas com os artistas, análises críticas, descrição dos processos de trabalho e propostas metodológicas) ${ }^{7}$.

No período 2012-2015 da rede House on Fire, foram desenvolvidos seis programas temáticos: 1- Art \& Politics; 2- Biopolitics Gender Politics and Transhumanism; 3- Cultural Diversity at a Crossroads; 4- Government, Conflict and War; 5- The Individual and the Common; 6- The Politics of Economy. Deste conjunto de programas, quatro abordam temas da atualidade nos quais estão inscritas diversas dimensões de problematização da sociedade (económica, cultural, de género, etc.); o Programa "Government, Conflict and War" é, por seu turno, relativo à Primeira Guerra Mundial, tendo sido realizado, no Lift Festival, em Londres, aquando do seu centenário, em 2014; o programa "The Individual and the Common" distingue-se dos demais por ter o seu foco numa problemática que, sendo fundamental nas ciências sociais e em particular na história da sociologia, veio a adquirir, desde final da década de 9o, o estatuto de debate re-emergente. Trata-se de um debate que inscreve "várias tentativas de superar a oposição indivíduo/coletivo", com particular incidência na "discussão de novos nomes para um sujeito político coletivo" - como por exemplo, a figura da plebe em Martin Breaugh, o conceito de multidão, de Toni Negri com Michael Hardt, ou em Paolo Virno - e, "em estreita proximidade, novos modos de pensar a forma comunidade" como é o caso de o "ser em comum" de Jean-Luc Nancy, direcionado ontologicamente para "assumir a dimensão em comum do próprio ser" (Dias \& Neves, 2010, pp. 377-378).

A natureza crítica da programação da House on Fire está bem patente nas designações dos muitos ciclos de eventos que compõem cada um dos seis programas temáticos ${ }^{8} \mathrm{e}$

\footnotetext{
7 House on Fire: detailed description of the action, s/d. (policopiado, 11 págs.). Ver a primeira publicação imprensa da House on Fire: Malzacher, F. (Ed.) (2015). Not just a mirror. Looking for the political theatre of today - Performing Urgency \#1. Santo Tirso: House on Fire.

${ }^{8}$ No período da programação $2012-2015$ da rede House on Fire, foram realizados um total de 29 ciclos de eventos,
} 
é regularmente levada à prática nos seus enunciados textuais de apresentação/divulgação9. A título ilustrativo, refiro seguidamente três exemplos de ciclos de eventos.

"Phantasm and Politics", um dos nove ciclos de eventos realizados no âmbito do programa "Art \& Politics", consistiu numa série de filmes, conferências e dez sessões de debate que tiveram lugar no Brut Viena (Áustria), ao longo de 2014, com uma periodicidade mensal. A sessão \#7 deste ciclo consistiu na apresentação do projeto "Truth is Concrete" que decorreu durante sete dias no Steirischer Herbst Festival, em setembro de 2012, em Graz, na Áustria, sob o lema "a arte deve ser um instrumento para mudar o mundo, ao invés de simplesmente refletir sobre ele"10. Com o mesmo título (Truth is concrete) veio a ser publicado um livro, organizado por um dos curadores do evento, o dramaturgo Florian Malzacher (2015), significativamente subintitulado Handbook for Artistic Strategies in Real Politics. Não estamos perante um caso isolado de viragem da arte para a realidade, mas sim em face da filosofia programática da nova Reality Trend, desenvolvida, nomeadamente, por Rimini Protokoll, com a qual a House on Fire tem estreita relação."

No quadro do programa "Biopolitics Gender Politics and Transhumanism, o ciclo de eventos Straight white men - a festival about privilege", com performances, debates, música, teatro, dança e filmes, realizado em 2014 e 2015 (em três dos dez teatros europeus da rede), constitui uma significativa declinação da peça intitulada "Straitght White Men", exibida no contexto deste ciclo pela Companhia norte-americana Young Jean Lee's Theater. Tendo como cenário uma sala de estar, algures num subúrbio da sociedade norte-americana, "um pai e os seus três filhos de meia idade devem confrontar-se com uma questão aparentemente simples: o que pode um privilegiado, heterossexual, homem e branco fazer para lutar contra a existência continuada de um sistema injusto?"12

Como parte do programa "The Individual and the Common", decorreu de setembro 2013 a abril 2014, no MM, o ciclo "There's no such thing as society". Reatualizando para o século XXI a famosa frase de Margaret Tatcher representativa do neo-liberalismo dos anos 1980, este ciclo de eventos relança o debate sobre a relação entre o indivíduo e o colectivo, fazendo-o em "quatro etapas" que interrogam as premissas da Revolução Francesa - solidariedade (dezembro 2013), fraternidade (março 2014) e liberdade (abril 2014) ${ }^{13}$. A encerrar a primeira etapa (introdução) de "There's no such thing as society", o psicólogo social alemão Harald Welzer apresentou num workshop (28 setembro de 2013) o projeto FuturZwei (Futuro Perfeito), instalado num site com o mesmo nome. Em contra-ciclo à mega-narrativa TINA - "There is no alternative" -, protagonizada por Tatcher, e atualizada na primeira década do nosso século, FuturZwei propõe-se dar visibilidade à

\footnotetext{
distribuídos pelos vários programas temáticos do modo seguinte: 1- Art \& Politics (9 ciclos); 2- Biopolitics Gender Politics and Transhumanism (3 ciclos); 3-Cultural Diversity at a Crossroads (4 ciclos); 4- Government, Conflict and War (3 ciclos); 5- The Individual and the Common ( 5 ciclos); 6- The Politics of Economy ( 5 ciclos).

9 Disponíveis nos programas impressos do Maria Matos - Teatro Municipal de Lisboa, de periodicidade bimestral, ou online através do site da House on Fire: http://www.houseonfire.eu/home

${ }^{10}$ Retirado de http://www.houseonfire.eu/home

"House on Fire: detailed description of the action, s/d. (policopiado, 11 págs.).

${ }^{12}$ Retirado de http://www.houseonfir.eu/

13 Ver Programa Maria Matos Teatro Municipal, setembro-outubro, 2013, p. 9.
} 
narrativa "Everybody can do something", convocando para a sua ação discursiva o elemento utópico de ruptura e abertura:

queremos dar visibilidade e credibilidade a histórias que contrariam a história que as sociedades capitalistas ocidentais divulgam sobre si próprias. A nossa utopia é tornarmo-nos uma agência de promoção de um movimento social que ainda não sabe da sua existência. (Programa Maria Matos Teatro Municipal, setembro-outubro, 2013, p. 19)

Ao ter participado no workshop de Harald Welzer, pude sintetizar o argumentário do seu projeto em três tópicos: primeiro, contrariar a vulgar relação causa-efeito entre o argumento de que "o sistema é complexo" e o argumento de que, por isso, "é muito complicado cada um de nós fazê-lo... (mudar)"; segundo, alterar a relação entre a teoria e a ação, quer por inversão desta ordem quer por demarcação de uma ética normalizadora da contradição entre ação e pensamento; terceiro, substituir a meganarrativa negativa que quantifica visões e previsões de catástrofes e escassez, sustentada pelo pensamento evolucionista de um futuro melhor, por um arquivo de "contra-narrativas" positivo, qualitativo e cumulativo de práticas alternativas "à sociedade de consumo e de desperdício" que no seu conjunto mostram "histórias sobre um futuro possível", que funcionem com o estatuto de first movers (que se quisermos podemos imitar) e que constituam simultaneamente "um incentivo a uma repolitização da esfera colectiva da vida".

\section{HOUSE ON Fire E ARTE COLABORATIVA}

O recurso a "repertórios de ação" ou o stock de meios de ação (Tilly, 1986), - no caso em estudo, temas, problemáticas, autores, teorias ou conceitos, e obras que sejam provenientes dos regimes discursivos científico e filosófico -, está presente na programação da House on Fire em diversas modalidades que passo a tipificar em cinco categorias, apresentadas aqui, ainda, com um estatuto exploratório.

As conferências/palestras protagonizadas por comunicantes provenientes das áreas da filosofia e de vários saberes científicos (sobretudo das áreas das ciências humanas e sociais) são uma modalidade regular e transversal aos vários programas de "Debate \& Pensamento" desenvolvidos pela House on Fire. Por exemplo, no contexto do programa temático "The Politics of Economy", decorreu, no Teatro Maria Matos, de abril a julho de 2013, o ciclo da "Transição"14 onde a sustentabilidade foi sucessivamente abordada por seis conferencistas ${ }^{15}$, versando, os recursos naturais, o trabalho, a comida, a economia, o ambiente e o estilo de vida.

\footnotetext{
${ }^{14} \mathrm{O}$ movimento da Transição, também conhecido por rede de transição (transition network), surgiu em 2005-2006 com Rob Hopkins e Naresh Giangrande que fundaram a Transition Town Totnes (a cidade de Totnes em Inglaterra). A Rede Transição (Transition Network) tem atualmente mais de mil iniciativas registadas nos cinco continentes. Retirado de https://transitionnetwork.org/

${ }^{5}$ Peter Tom Jones (engenheiro), "The transition to a low-carbon circular economy", 3 de abril, 2013; Anselm Jappe (filósofo), "Après la fin du travail: vers une humanité superflue?" 23 abril, 2013; Carolyn Steel (arquitecta), "Sitopia - the transformative power of food", 21 de maio 2013; Paulo Magalhães (jurista), "O desafio de nos organizarmos como vizinhos globais", 5 de junho, 2013; Tim Jackson (economista), "Prosperity and sustainability in a green economy", 24 de junho, 2013; Viriato Soromenho Marques (filósofo), "Riscos e oportunidades numa era de transição para a sustentabilidade", 16 de julho, 2013.
} 
A presença de determinados pensadores como catalizadores de ciclos de eventos, advindos das áreas da ciência e da filosofia, constitui uma segunda modalidade, embora tendo um estatuto extraordinário, em contraste com a regularidade da primeira, acima considerada. Foi o caso do ciclo "Gender trouble - performance, performatividade e política de género", que teve lugar, também, no Teatro Maria Matos, de maio a julho de 2015, e que foi dedicado aos 25 anos da publicação, em 1990, do livro de Judith Butler, Gender Trouble. Feminism and the subversion of identity, tendo contado, ao mesmo tempo, com a sua presença, a 2 de junho, como conferencista ${ }^{16}$.

Uma terceira modalidade assenta na centralidade de determinados autores/obras como bases para a concepção de projetos artísticos. A título de exemplo, refira-se o trabalho de vídeo-arte, Dancing Gender Trouble do coletivo espanhol formado por Helena Cabello \& Ana Carceller, exibido no ciclo de eventos que teve como catalisador a figura de Butler e que consistiu numa performance coletiva de tradução física dos conteúdos dos livro icónico da filósofa, por participantes sem experiência em dança, onde as palavras de Gender Trouble foram sendo ditas no lugar da música.

A colaboração de académicos na concepção de projetos artísticos é uma quarta modalidade que traduz bem uma cultura de transposição da tradicional divisão institucional entre trabalho científico e trabalho artístico. De modo ilustrativo, no ciclo temático There's no such thing as society, decorrido (entre setembro de 2013 e abril de 2014) no Maria Matos, como parte do programa "The Individual and the Common, foi exibida a peça de teatro Some use for your broken clay pots", de Christophe Meierhans. Com o apoio de académicos das áreas da ciência política e do constitucionalismo, Meierhans (2014) cria uma nova constituição que serve de base para a peça propriamente dita e que é, também, corporizada num livro multilingue (em francês, inglês, holandês e alemão).

Como esclarece o artista, "esta peça é inspirada no ostracismo que vigorou na cidade antiga de Atenas, como sistema que permitia aos cidadãos, a cada ano, banir da cidade um líder político que fosse considerado prejudicial para o governo da cidade" (Teatro Maria Matos, 2016). Os "nomes das pessoas a expulsar" eram supostamente "gravados ou em conchas de ostras (do grego: ostreon) ou em pedaços de barro partido (ostraka)" (Teatro Maria Matos, 2016), sendo este segundo sentido que explica o título escolhido: "algum uso para os seus vasos de barro partidos".

Some use for your broken clay pots adquire igualmente alguns dos contornos da conferência-performance, a quinta modalidade que aqui tipifico como sendo caracterizada pela hibridação da prática artística com a prática académica. A peça de Meierhans é uma conferência (de imprensa) em discurso direto, suportado pelo recurso a um projetor de acetatos, dirigida a um público que é "colocado no papel de eleitor", cabendo-lhe "imaginar que tipo de cidadãos e que tipo de sociedade" a constituição alternativa que lhes é apresentada "poderia produzir" (Teatro Maria Matos, 2016).

"Lecture for everyone", da artista Sarah Vanhee é um outro exemplo de conferência-performance, que ocorreu no mesmo ciclo de eventos ("There's no such thing as

\footnotetext{
${ }^{16}$ Mais recentemente, o ciclo "As três ecologias", que teve lugar, entre março e abril de 2016, no MM, em Lisboa, teve como catalizador a obra com o mesmo título, Les Trois écologies (1989) de Félix Guattari, da qual retoma a ideia de interligar as três dimensões da ecologia, pessoal, social e ambiental, enunciadas pelo filósofo francês.
} 
society"), na cidade de Lisboa, entre 7 e 14 de dezembro de 2013. Em contextos organizacionais e associativos muito variados (coro Gulbenkian, Fundação do Gil, Goethe Institut, Universidade Nova - Scholl of Business and Economics, Academia de Música de Santa Cecília, Vodafone, Câmara Municipal de Lisboa, etc.), "a artista infiltra-se em situações de reunião ou assembleia" (Mora, 2016, p. 8): um ensaio de oratória de natal de J.S. Bach, uma reunião de equipa, uma reunião de professores para discussão de notas dos alunos; um seminário de doutorandos, uma reunião de funcionários para a organização de um jantar de natal, uma sessão clínica de um serviço de medicina, etc. Imediatamente após ter dado uma conferencia de 15 minutos cujo texto não difere de contexto para contexto e cujo conteúdo é um "híbrido de histórias e reflexões políticas com um impulso performativo" (Vanhee citada em Mora, 2016, p. 8), a artista, sem comunicar com as pessoas, ausenta-se da reunião. Pode entender-se esta conferência-performance como "uma ilustração de um momento utópico: um fragmento espácio-temporal por meio do qual a artista procura que a 'abertura aos possíveis laterais'" à razão de ser da reunião ou "à sua ordem de trabalhos possa despontar" (Mora, 2016, p. 8).

Para uma arqueologia das conferências performativas, há que considerar como primeiras referências Robert Morris, John Cage ou Joseph Beuys. Na sua performance, intitulada 21.3, datada de 1964, Morris apresenta-se como se fosse um professor, com uma indumentária formal, num contexto igualmente formal, com o púlpito, o microfone, um jarro e um copo de água, dando uma aula teórica, sobre a introdução do conhecido ensaio de Erwin Panofsky sobre iconografia e iconologia, intitulado Estudos em Iconologia e datado de 1939 (Blasco, 2013, pp. 13-14). O discurso oral e direto, ao invés da performance predominantemente corporal, e a sua encenação com recurso a suportes materiais de apoio (neste caso, remissíveis para aqueles que são os mais clássicos no contexto académico, mas podendo igualmente tratar-se do audiovisual, do power point ou de outros meios) são, segundo Olveira, dois dos traços de caracterização da conferência-performance (ver Olveira, 2014, pp. 7-10). O estatuto de prática de fronteira ou de prática entre artistas e a académicos, que através dos dois traços mencionados podemos reconhecer na conferência-performance, é igualmente remissível para a indistinção de públicos aos quais esta se dirige, pois tanto atua para académicos quanto para não-académicos. A este respeito, um outro traço recorrente na conferência-performance é a interação, a conversação, a participação do público. Para além destas e de outras características (ver Olveira, 2014, p. 10), é sobretudo importante salientar que a modalidade conferência-performance torna-se política quando é uma prática de ação crítica que se exerce pela desconstrução e/ou subversão de códigos hegemónicos, como é o caso clássico de 21.3 de Morris.

\section{CONSIDERAÇõES FINAIS}

Sobre o período 2012-2015 da programação da rede House on Fire, poder-se-iam trazer aqui outros registos da presença das cinco modalidades de colaboração entre cultura artística e cultura científico-social e filosófica que o percurso de investigação 
realizado possibilitou definir. Porém, no pressuposto de que só o estudo continuado, expandido e aprofundado dos casos que as exemplificam permitirá, no futuro, avaliar substantivamente o poder de a House on Fire desestabilizar a tradicional divisão institucional do trabalho entre cultura artística e cultura científico-filosófica.

A potência política da House on Fire foi equacionada no cruzamento do que se considerou ser as quatro tendências que marcam as práticas de arte política na atualidade: a "viragem social", a urgência da realidade, o impulso utópico e as práticas colaborativas. É, todavia, de admitir que para uma explicação mais aprofundada do papel dos agentes artístico-culturais no desenvolvimento da arte política, também, deve ser considerada a importância das políticas públicas, em várias escalas de poder (municipal, nacional, supranacional), no seu papel (re)configurador dos projetos artístico-culturais enquanto objetos, instrumentos, ou resultados da sua ação. De qualquer modo, através do percurso de investigação efetuado, a House on Fire foi identificada como um caso consistente de arte política, relativamente ao qual se salientou a importância institucional do MM enquanto seu polo discursivo.

Por último, é de assinalar que a estrutura em rede, em simultâneo com a delimitação europeia da programação coproduzida e exibida pelos dez teatros e festivais da House on Fire, ao re-situar o MM à escala inter-nacional e europeia, convida ao apontamento da questão seguinte: qual o potencial alternativo (no sentido político) que as redes artístico-culturais europeias (das quais a House on Fire é um caso, entre outros) podem, ou não, estar a inscrever no contexto cultural da sociedade portuguesa? /

\section{REFERÊNCIAS BIBLIOGRÁFICAS}

Bernardo, L. (Ed.) (2015). Correntes invisíveis. Neoloberalimo no século XXI. s/l: Deriva Editores.

Bhabha, H. (1998). Conversational art. In M. J. Jacob \& M. Brenson (Eds.), Conversations at the Castle: Changing Audiences and Contemporary Art (pp. 38-47). Cambridge, Mass e Londres: MIT Press.

Bishop, C. (2006). The social turn: colaboration and its discontents. ARTFORUM, 178-183.

Bishop, C. (2012). Artificial hells: participatory art and the politics of spectatorship. Londres e Nova lorque: Verso.

Blasco, S. (2013). Mantener las formas. La academia en y desde las prácticas artísticas. In S. Blasco (Ed.), Investigación artística y universidade: materiales para un debate (pp. 11-41). Madrid: Ediciones Asimétricas.

Bloch, E. (1995). The principle of hope. Cambridge: Mass/ MIT Press.

Borges, Sofia (2012). Quando o artista decide abrir a porta do seu atelier e começa a olhar à sua volta. Revista Crítica de Ciências Sociais, 99, 185-202. doi: 104000/rccs.5157

Bourriaud, N. (1998). L'esthétique relationnelle. Dijon: Les Presses du réel.

Cardoso, I. L. e Lobo, P. (2013). O paraíso é aqui e agora: busca, construção e perda da utopia. Notas sobre política, arte e globalização. In M. Acciaiuoli; A. D. Rodrigues; M. J. Castro; P. André \& P. S. Rodrigues (Eds.), Arte Q Utopia (pp. 309-322). Várzea da Rainha: Várzea da Rainha Impressores, S.A. 
Carmo, A. (2014). Cidade e cidadania (através da Arte). O Teatro do Oprimido na região metropolitana de Lisboa. Tese de doutoramento. Universidade de Lisboa /Instituto de Geografia e Ordenamento do Território, Portugal (policopiado).

Deputter, M. (2014). Maria Matos Teatro Municipal Outubro 2014 - Setembro 2018 - Proposta artísticocultural, 16 junho.

Dias, B. P. \& Neves, J. (Ed.) (2010). A política dos muitos. Povo, classes e multidão. Lisboa: Tinta da Chna.

Finkelpearl, T. (2000). Dialogues in puin dialogical relation public art. Massachusetts/Londres: The MIT Press.

Guattari, F. (1989). Les trois écologies. Paris: Éditions Galilée.

Hand, B. (2010). A struggle at the roots of the mind: service and solidarity in dialogical relational and collaborative perspectives within contemporary art. In IMMA, What is participatory and relational art? (pp. 8-17). Dublin: Irish Museum of Modern Art - IMMA.

Kester, G. (2005). Conversation pieces: The role of dialogue in socially-engaged art. In Z. Kucor \& S. Leung (Eds.), Theory in Contemporary art since 1985 (pp. 76-100). Oxford: Blackwell.

Kester, G. (2011). The one contemporary collaborative art and the many in a global context. Durham, N.C.: Duke University Press.

Keucheyan, R. (2013). Hémisphère gauche. Une cartographie des nouvelles pensées critiques. Paris: Éditions La Découverte.

Lacy, S. (1995). Mapping the terrain: New genre public art. Seattle: Bay Press.

Malzacher, F. (2015). Putting the urinal back in the Restroom - The symbolic and the direct power of art and activism. In F. Malzacher (Ed.), Truth is Concrete - a Handbook for Artistic Strategies in Real Politics (pp. 12-25). Berlim: Steirischer Herbst /Strenberg Press.

Malzacher, F. (Ed.) (2015). Not just a mirror. Looking for the political theatre of today - Performing Urgency \#1. Santo Tirso: House on Fire.

Meierhans, C. (2014). Some use for your broken clay pots. Gent: Mer.

Mora, T. (2016). The individual and the common: arte política e crítica social. In Portugal: Território de territórios. Atas do IX Congresso Português de Sociologia. Lisboa: Associação Portuguesa de Sociologia.

Mora, T. (2009). Viagem, utopia e insularidade: narrativas fundadoras da ciência e da sociedade moderna. Lisboa: Fundação Calouste Gulbenkian/ Fundação para a Ciência e Tecnologia.

Olveira, M. (Ed.) (2014). Conferencia performativa. Nuevos formatos, lugares, prácticas y comportamentos artísticos. Castilla e Léon/Madrid: MUSAC/ This Side Up.

Ribeiro, A. P. (Ed.) (2013). Grandes Lições. vol. 1, vol. 2. Lisboa: Fundação Calouste Gulbenkian.

Rodríguez, A. (2012). Viragem pedagógica, capitalismo cognitivo, nova institucionalidade. Imprópria, 1, 39-42.

Ruyer, R. (1950). L'utopie et les utopies. Paris: PUF.

Teatro Maria Matos (2016). Some use for your broken clay pots - Lisboa, 5, 7 e 8 de março. Folha de Sala.

Tilly, C. (1986). La France conteste. De 1600 à nous jours. Paris: Fayard.

Unipop (Ed.) (2014). Pensamento crítico contemporâneo. Lisboa: Edições 70. 


\section{NotA BIOGRÁFICA}

Teresa Mora é investigadora do Centro Interdisciplinar de Ciências Sociais (CICS-UMinho) e professora auxiliar no Departamento de Sociologia da Universidade do Minho. Doutorada em sociologia pela Universidade do Minho (em 2007), com um trabalho sobre similitudes entre teoria social e utopias sociais, de que resultou, entre outras, as publicações seguintes:

- Mora, T. (2013). Classics of Sociology and Modern Social Utopias: Displacing Knowledge Boundaries. In J. Bastos da Silva (Ed.), The Epistemology of Utopia: Rhetoric, Theory and Imagination (pp. 65-79). Newcastle upon Tyne: Cambridge Scholars Publishing. ISBN (10): 1-4438-4625-2, ISBN (13): 978-1-4438-4625-7

- Mora, T. (2009). Viagem, utopia e insularidade: narrativas fundadoras da ciência e da sociedade moderna. Lisboa: Fundação Calouste Gulbenkian/ Fundação para a Ciência e Tecnologia. ISBN: 978-972-31-1272-6

Os seus interesses de investigação centram-se atualmente na arte política e social, com enfoque particular nas práticas colaborativas entre artistas e cientistas sociais.

E-mail: tmora@ics.uminho.pt

Centro Interdisciplinar de Ciências Sociais (CICS-UMinho) - Instituto de Ciências Sociais - Universidade do Minho, Campus de Gualtar, 4710-057 Braga, Portugal

* Submetido: 15-10-2016

*Aceite: 21-01-2017 